\title{
Impact of sex on response to neoadjuvant chemotherapy in patients with bladder cancer
}

\author{
David D'Andrea ${ }^{1}$, Peter C Black ${ }^{2}$, Homayoun Zargar ${ }^{2,3}$, Kamran Zargar-Shoshtari ${ }^{4,5}$, Sonja Zehetmayer ${ }^{6}$, \\ Adrian S Fairey ${ }^{7}$, Laura S Mertens ${ }^{8}$, Colin P Dinney ${ }^{9}$, Maria C Mir ${ }^{10,11}$, Laura-Maria Krabbe ${ }^{12,13}$, Michael \\ S Cookson ${ }^{14}$, Niels-Erik Jacobsen ${ }^{7}$, Jeffrey S Montgomery ${ }^{15}$, Nikhil Vasdev ${ }^{16,17}$, Evan Y Yu ${ }^{18}$, Evanguelos \\ Xylinas $^{19}$, Nicholas J Campain ${ }^{20}$, Wassim Kassouf ${ }^{21}$, Marc A Dall'Era ${ }^{22}$, Jo-An Seah ${ }^{23}$, Cesar E Ercole ${ }^{10}$, \\ Simon Horenblas ${ }^{8}$, Srikala S Sridhar ${ }^{23}$, John S McGrath ${ }^{20}$, Jonathan Aning ${ }^{20,24}$, Jonathan L Wright ${ }^{25}$, \\ Andrew C Thorpe ${ }^{17}$, Todd M Morgan ${ }^{15}$, Jeff M Holzbeierlein ${ }^{26}$, Trinity J Bivalacqua ${ }^{27}$, Scott North ${ }^{28,29}$, \\ Daniel A Barocas ${ }^{30}$, Yair Lotan ${ }^{12}$, Petros Grivas ${ }^{18,31}$, Andrew J Stephenson ${ }^{10}$, Jay B Shah ${ }^{9,32}$, Bas W van \\ Rhijn $^{8}$, Siamak Daneshmand ${ }^{33}$, Philippe E Spiess ${ }^{4}$, Shahrokh F. Shariat ${ }^{1,12,34,35,36}$
}

1. Department of Urology, Comprehensive Cancer Center, Medical University of Vienna, Vienna, Austria

2. Department of Urologic Sciences, University of British Columbia, Vancouver, BC, Canada

3. Western Health, Melbourne, Australia

4. Department of Genitourinary Oncology, H Lee Moffitt Cancer Center and Research Institute, Tampa FL, USA

5. University of Auckland, Auckland, New Zealand

6. Center for Medical Statistics, Informatics, and Intelligent Systems, Medical University of Vienna, Vienna, Austria

7. University of Alberta, Edmonton, AB, Canada

8. Department of Urology, The Netherlands Cancer Institute - Antoni van Leeuwenhoek Hospital, Amsterdam, The Netherlands

9. Department of Urology, MD Anderson Cancer Center, Houston, TX, USA

10. Glickman Urological and Kidney Institute, Cleveland Clinic, Cleveland, $\mathrm{OH}, \mathrm{USA}$

11. Department of Urology, Fundacion Instituto Valenciano de Oncologia, Valencia, Spain

12. Department of Urology, University of Texas Southwestern Medical Center, Dallas, TX, USA

13. Department of Urology, University of Münster, Münster, Germany

14. Department of Urology, University of Oklahoma College of Medicine, Oklahoma City, OK, USA

15. Department of Urology, University of Michigan Health System, Ann Arbor, MI

16. Hertfordshire and Bedfordshire Urological Cancer Centre, Department of Urology, Lister Hospital, Stevenage, UK

17. Department of Urology, Freeman Hospital, Newcastle Upon Tyne, UK

18. Department of Medicine, Division of Oncology, University of Washington School of Medicine and Fred Hutchinson Cancer Research Center, Seattle, WA, USA

19. Department of Urology, Cochin Hospital, APHP, Paris Descartes University, Paris, France

20. Department of Surgery, Exeter Surgical Health Services Research Unit, Royal Devon and Exeter NHS Trust, Exeter, UK

21. Department of Surgery (Division of Urology), McGill University Health Center, Montreal, Canada

22. Department of Urology, University of California at Davis, Davis Medical Center, Sacramento, CA, USA

23. Princess Margaret Hospital, Toronto, ON, Canada

24. Bristol Urological Institute, North Bristol NHS Trust, Bristol, UK

25. Department of Urology, University of Washington, Seattle, WA, USA

26. Department of Urology, University of Kansas Medical Center, Kansas City, KS, USA

27. Department of Urology, The James Buchanan Brady Urological Institute, The Johns Hopkins School of Medicine, Baltimore, MD, USA

28. Cross Cancer Institute, Edmonton, AB, Canada

29. Department of Oncology, University of Alberta, Edmonton AB, Canada

30. Department of Urology, Vanderbilt University Medical Center, Nashville, TN, USA

31. Department of Hematology and Medical Oncology, Taussig Cancer Institute, Cleveland Clinic

32. Department of Urology, Stanford University School of Medicine, Stanford, CA, USA

33. USC/Norris Comprehensive Cancer Center, Institute of Urology, University of Southern California, CA, USA

34. Departments of Urology, Weill Cornell Medical College, New York, New York, USA 
35. Department of Urology, Second Faculty of Medicine, Charles University, Prag, Czech Republic

36. Institute for Urology and Reproductive Health, I.M. Sechenov First Moscow State Medical University, Moscow, Russia

Please direct correspondence to:

Shahrokh F. Shariat

Department of Urology, Medical University of Vienna

Währinger Gürtel 18-20

1090 Vienna

Austria

Tel +434040026150

sfshariat@gmail.com 


\section{ABSTRACT}

2 Objective: To assess the effect of patient's sex on response to neoadjuvant chemotherapy (NAC) in patients with clinically non-metastatic muscle-invasive bladder cancer (MIBC).

Methods: Complete pathologic response, defined as ypTONO at radical cystectomy, and downstaging were evaluated using sex-adjusted univariable and multivariable logistic regression modeling. We used interaction terms to account for age of menopause and smoking status. The association of sex with overall (OS) and cancer-specific survival (CSS) was evaluated using Cox regression analyses. Results: A total of 1031 patients were included in the analysis, 227 (22\%) of whom were female. Female patients had a higher rate of extravesical disease extension $(p=0.01)$. After the administration of NAC, ypT stage was equally distributed between sexes $(p=0.39)$. On multivariable logistic regression analyses, there was no difference between the sexes or [age of menopause] with regards to ypTONO rates or downstaging (all p >0.5). On Cox regression analyses, sex was associated with neither OS $(1.04,95 \% \mathrm{Cl}$

$0.75-1.45$ .45, $p=0.81$ Conclusion: Our study generates the hypothesis that NAC may equalize the preoperative disparity in clinical stage between men and women, suggesting a possible differential response between sexes. suggesting that females might respond better to NAC. This might be the explanation underlying the comparable pathologic stage and outcomes between sexes and needs to be tested prospectively. 


\section{Introduction}

20 Patient sex (female vs male) has a differential effect on bladder cancer (BCa) presentation and

21 survival[1, 2]. While BCa incidence is three to four times higher in males compared to females, the

22 latter are more likely to be diagnosed with advanced disease and to suffer from worse survival

23 outcomes despite standard treatment[3-5]. Neoadjuvant chemotherapy (NAC) is part of the standard

24 of care therapeutic modalities delivered in patients with clinically non-metastatic muscle-invasive BCa

25 (MIBC)[6, 7]. However, females are less likely to receive NAC which is partially explained by

26 differences in health care factors like time to diagnosis and treatment modality[8-11].

27 To the best of our knowledge, there is no data on a potentially differential response to NAC according 28 to sex in patients treated with radical cystectomy (RC). To fill this gap, we compared pathologic 29 30 31 for BCa. 


\section{Material and methods}

\section{Study population}

35 We performed a retrospective analysis of our multi institutional database comprising 1474 patients treated with NAC followed by RC for BCa from 2000 to 2013 [7].

37 Patients with clinically metastatic disease $(\mathrm{N}+$ and/or $\mathrm{M}+)$ were excluded, leaving 1031 patients for final analysis. A total of 313 patients were lost to follow-up, leaving 718 patients for survival analyses. Clinical stage prior to the administration of chemotherapy was assigned by the treating physician based on transurethral resection of the bladder, bimanual exam and/or cross-sectional imaging.

\section{Chemotherapy}

NAC regimens consisted of cisplatin-based combination chemotherapy, or other. Chemotherapy regimen and number of cycles were administered at clinician discretion in accordance with institutional standards and guidelines at that time.

\section{Radical cystectomy}

Patients were treated with RC and lymphadenectomy. All procedures were performed by an open technique. The decision for the type of urinary diversions was based on patient and disease characteristics, patient's and surgeon's preferences as well as patient's performance status. All surgical specimens were processed according to standard pathologic procedures and staged according to the 1998 TNM classification. All tumors were high-grade.

\section{Outcome measurement}

Response to NAC was assessed by yTNM stage at RC. Complete pathologic response was defined as ypTONO. Downstaging was defined as any stage migration from non-organ confined disease (NOC) to ypT2-NO, ypNMIBC-NO or ypTO-NO or from cT2 to ypNMIBC-NO or ypTO-NO. Overall survival (OS) and cancer-specific survival (CSS) were calculated from the day of RC death of any cause for OS and death due to bladder cancer for CSS, respectively. Patients were censored at the time of last follow up. Cause of death was recorded through patients charts and/or death certificates [12]. 


\section{Molecular correlates of response to chemotherapy}

Since both RNA expression subtypes and mutations in specific DNA damage response (DDR) genes have been shown to correlate with response to NAC in patients with MIBC, we investigated the prevalence of subtypes and DDR gene alterations according to sex using data from 395 chemo-naïve patients with MIBC from The Cancer Genome Atlas Program (TCGA)[13]. The TCGA subtypes (luminal papillary, luminal infiltrated, luminal, basal squamous and neuronal) were used. We selected ERCC2[14] as well as RB1, ATM and FANCC[15] as key DDR genes based on prior reports, but also added ATR, BRCA1, BRCA2, ERCC5, RAD51C, and REQLC4 based on the list of DDR genes selected as functionally important in three ongoing trials investigating bladder preservation (NCT03609216, NCT03558087, NCT02710734)[16-18].

\section{Statistical analysis}

We performed a stepwise approach to the statistical analyses. First, we performed multiple imputation by using chained equations to handle missing data that were assumed to be missing at random. Fifteen imputed data sets were generated using predictive mean matching for numeric variables, logistic regression for binary variables and Bayesian polytomous regression for factor variables. Second, we compared the distribution of patients' clinicopathologic features according to sex. Third, we evaluated the association of sex with pathologic response using univariable and multivariable logistic regression modeling. Due to the even distribution of the data between groups, adjustments using propensity score were not performed. Fourth, as pre-planned analysis, we introduced interaction terms in the logistic models to evaluate the synergistic effect of sex and smoking status or menopausal status. As the age of menopause was not available, we arbitrarily assigned the age of 50 as cut-off for menopause. Fifth, we investigated the association of sex with OS and CSS using Cox regression analyses and plotted survival curves using the Kaplan-Meier method. Sixth, we tested the validity of the Cox model assumption using Shoenfeld residuals. Due to the exploratory character of the study, statistical significance was considered at $p<0.05$, but not in a confirmatory manner. Therefore, no adjustment for multiplicity was performed. All tests were performed with R (R Foundation for Statistical Computing, v3.5.1). 


\section{Results}

Clinico-pathologic features of the population are shown in Table 1. Overall, 804 (78\%) patients were of male sex and 227 (22\%) were of female sex. Females had more advanced clinical stage at presentation than their male counterparts (NOC disease 36.6 vs $32.6 \%$

We observed an equal distribution of ypT stage between sexes after NAC (Figure 1). On univariable logistic regression analyses, we could not identify an association of sex with downstaging or complete pathologic response to NAC (all $p>0.5$ ). Multivariable analyses which adjusted for the effects of clinical stage, administered NAC regimen, number of cycles, and smoking status, failed to identify a significant difference between females and males in downstaging or complete pathologic response to NAC when comparing the means between the two populations in the overall model (all $p>0.5)$ (Table 2).

Overall, 207 (91\%) female patients were 50 years or older. Of these, 91 (44\%) were never smokers, 109 (53\%) former smokers and 7 (3\%) current smokers. On univariable and multivariable logistic regression analyses, we could not identify an association of menopausal status with complete response to NAC or downstaging (all p >0.5) (Table 3).

Within a median follow-up of 17 months (IQR 7 - 37), 297 (41\%) patients died and 206 (29\%) died of their BCa. On Cox regression analyses, female sex was neither associated with OS ( $\mathrm{HR} 0.98,95 \% \mathrm{Cl}$ $0.69-1.38, p=0.89)$ nor CSS (HR 1.03, 95\% Cl $0.69-1.55, p=0.88$ ) (Figure 2). The validity of the proportional hazard assumption was supported by a non-significant relationship between residuals and time $(p=0.99)$.

In a final step, we extracted TCGA data[13] and analyzed the prevalence of ten DDR genes (ATM, ATR, BRCA1, BRCA2, ERCC2, ERCC5, FANCC, RAD51C, RB1 and REQLC4) between males and females. We found that females have fewer DDR gene mutations overall compared to males $(28.3 \%$ vs $44.6 \%$, p < 0.001). However, there was no difference in the rate of single DDR gene mutations between sexes (supplementary Figure S1). With respect to RNA-based subtypes, basal-squamous was more frequent 
121 in females (43.4\% vs $37.7 \%)$ and luminal papillary in males (37.7\% vs $28.3 \%$ ). However, these 122 differences were not statistically significant (all $p \geq 0.05$, Supplementary figure S2). 


\section{Discussion}

124 In a retrospective analysis of a large multicenter cohort of patients treated with NAC followed by RC

125 for non-metastatic BCa, we could not observe any association of sex with pathologic complete 126 response to NAC. While there was a small but statistically significant difference in clinical T stage at 127 diagnosis, this difference between sexes could no longer be observed after NAC.

128

129 Although the incidence of BCa in females is lower than in males, female patients often present with 130 more advanced disease and suffer from worse prognosis $[1,2,19]$. In this context, genetic, environmental, hormonal and health care differences are known to play a role in response to standard therapies and oncologic outcomes $[8,20]$. However, a definitive and satisfactory explanation for these sex-based differences is still missing. We tried to shed light on this, by investigating the synergistic effect of smoking and cut-off age of 50, as surrogate for menopause[21], on response to NAC. We found no association of either age or smoking status with response to NAC. Notably, a metaanalysis showed that the magnitude of benefit to immune checkpoint inhibitors may be higher in men than women, but only one trial of patients with advanced urothelial carcinoma was included in that [22]. However, less than $10 \%$ of the women in this cohort were under age 50 and a difference may be difficult to identify.

Smoking is a well-known risk factor for $\mathrm{BCa}[23,24]$. Population-based studies have shown that among smokers, females have a higher risk of developing BCa compared to males (HR 2.75 for female vs 2.32 for male)[25]. However, the synergistic effect of smoking and sex is not consistent in the literature $[26,27]$. In pre-clinical studies, smoking has been linked to chemo-resistance in human BCa cell line[28]. However, the clinical literature presents controversial results regarding smoking status as predictor of chemo-resistance, even when stratified by sex [29-32].

In our study, we expanded upon previous findings by investigating the synergistic effect of smoking and sex on the response to NAC in a large population with clinically non-metastatic MIBC. We could not identify a statistically significant association of smoking status with downstaging or complete response to NAC. This effect can partially be explained by the low patient number in relation to the difference between groups. Indeed, if we look at the reported effect in population-based studies[25, 
153

154

155

156

157

158

159

160

161

162

163

164

165

166

167

168

169

170

171

172

173

174

175

176

177

178

179

180

181

182

33], a larger cohort would, probably, be needed to show a statistically significant difference between males and females.

Preclinical studies have shown that the modulation of circulating estrogen levels through the menopausal status leads to structural changes in the murine bladder [30, 31]. In clinical studies, sexbased differences in hormonal status have been linked to the development and progression of $\mathrm{BCa}$ $[34,35]$.

We investigated the association of age, using the cut-off of 50 years as surrogate for menopause, with pathological response to NAC. We, indeed, found no significant association with any of the outcomes. These findings are in line with the current literature. For example, in a case-control-study with a meta-analysis, Dietrich et al. found that postmenopausal females were at higher risk for developing a $\mathrm{BCa}$, but this association was not statistically significant (OR $1.30,95 \% \mathrm{Cl} 0.45-3.77$ ). Those authors also reported that the OR increased with the age of menopause of $<45$ years (OR $1.33,95 \% \mathrm{Cl} 0.72-$ 2.47)[36]; but again, this association was not significant. Differences in tumor biology, change in sex steroid receptor after menopause and the potential association of BCa with sex steroid hormones may explain this phenomenon[37].

Somatic genetic alterations in DDR genes and molecular subtypes have been linked to clinical response to cisplatin-based $\operatorname{NAC}[14,15,38]$. Choi et al. have also reported that tumors of the basal subtype, which appear to benefit most from NAC, are enriched in women[38]. In order to evaluate whether differences in these two molecular parameters could explain the differential response to NAC in female, we analyzed the TCGA data. We found that men had overall more DDR gene mutations than females; however, it can be hard to ascertain the functional impact of each mutation.. Moreover, we could not identify a ssignificant difference in the rate of single DDR gene mutations or prevalence of mRNA cluster between sexes. Altogether, these molecular findings do not clearly explain the modest differential response rate to NAC between males and females.

Complete pathologic response after NAC has been correlated with improved OS and RFS $[39,40]$. We investigated the association of sex with survival and found no statistical difference in OS and CSS. In contrast to our findings, in a retrospective analysis of 4,216 patients treated with RC without NAC, 
183

Messer et al. found a significant association of female sex with recurrence $(p=0.039)$ and $\operatorname{CSS}(p=$ 0.001) [41]. The explanation for these disparities is likely multifactorial[1, 2, 42]. In our study, all patients were treated with NAC, which might have potentially abrogated clinical differences in survival. Indeed, we observed no difference in pathologic T or N stage between sexes after NAC. This is an important finding which generates the hypothesis that sex-based differences in clinical and pathologic features in BCa might be potentially equalized through the administration of NAC, leading to comparable oncologic outcomes.

We acknowledge the limitations of our study, which are mainly inherent to its retrospective design and the short follow-up. Staging and the administration of NAC were not standardized. Moreover, we could not account for the quality of surgical techniques. Indeed, the extent of the resection may have possibly influenced outcomes. Previous reports could not show a significant difference between sexes in patients treated with incomplete or complete TURB before NAC. For example, James et al. investigated the association of maximal TURB with complete pathologic response to NAC. Among 81 patients who received NAC, those treated with maximal TURB were more likely to achieve complete pathologic response (OR 3.17, 95\% Cl $1.02-9.83)$. Stratified by sex, females were more likely to achieve complete pathologic response. However, this association was statistically not significant [43]. In addition, the anatomic difference in bladder wall thickness between males and females could also have influenced outcomes by allowing a more radical resection in females.

In this context, it can be argued that nodal staging could be a more accurate end-point to assess response to NAC, as lymph nodes are not affected by any surgical intervention prior to NAC administration. In a previous retrospective analysis of 304 patients with clinically N+ treated with induction chemotherapy followed by $\mathrm{RC}$, we found that a complete pathological response can be achieved in $14.5 \%$ of the patients. However, the authors could not detect any differences in response to chemotherapy between sexes[44]. Finally, this study did not evaluate the association of sex with NAC related toxicity, morbidity and mortality.

Despite these limitations, our study provides clinically relevant information and generates the hypothesis that NAC could reduce the survival gap between males and females by equalizing sex- 
213 specific differences in clinical stage emphasizing the adoption of multimodal treatment modalities in 214 the era of personalized medicine[45].

215 


\section{Conclusion}

217 We found that, in patients planned for NAC and RC, females have worse clinico-pathologic features

218 compared to males at the time of diagnosis. After the administration of NAC there was no difference

219 in pathologic stage. Our analyses generate the hypothesis of a differential response to NAC between

220 sexes which could potentially equalize the clinical outcomes of patients with different prognosis.

221 Further research should focus on testing that hypothesis, as well as on sex-based differences in

222 response to novel systemic agents, such as immune checkpoint and FGFR inhibitors, as well as

223 trimodality therapy[46].

224

225

226

227

Aknowledgment

228 Program 


\begin{tabular}{|c|c|c|c|}
\hline & Male & female & $p$ \\
\hline$n(\%)$ & $804(78)$ & $227(22)$ & \\
\hline Age, median (IQR) & $63(57-71)$ & $65(58-72)$ & 0.11 \\
\hline Smoking, n (\%) & & & 0.02 \\
\hline Never & $292(36.3)$ & $100(44.1)$ & \\
\hline Former & $451(56.1)$ & $119(52.4)$ & \\
\hline Current & $61(7.6)$ & $8(3.5)$ & \\
\hline Histology, n (\%) & & & 0.98 \\
\hline Urothelial & $705(87.7)$ & $201(88.5)$ & \\
\hline Mixed histological variant* & 99 (12.3) & 26 (11.5) & \\
\hline Chemotherapy regimen, $\mathrm{n}(\%)$ & & & 0.73 \\
\hline Cisplatin-based & $670(83.3)$ & $192(84.6)$ & \\
\hline Other & $134(16.7)$ & $35(15.4)$ & \\
\hline Chemotherapy cycles, $n(\%)$ & & & 0.13 \\
\hline 1 to 2 & $76(9.5)$ & 32 (14.1) & \\
\hline 3 to 4 & $679(84.5)$ & $182(80.2)$ & \\
\hline 5 to 8 & $49(6.1)$ & $13(5.7)$ & \\
\hline cT, n (\%) & & & 0.01 \\
\hline CT2 & $510(63.4)$ & 131 (57.7) & \\
\hline cT3 & $195(24.3)$ & 77 (33.9) & \\
\hline cT4 & 99 (12.3) & $19(8.4)$ & \\
\hline ypT, n (\%) & & & 0.39 \\
\hline урт0 & $190(23.6)$ & $48(21.1)$ & \\
\hline ypNMIBC & $164(20.4)$ & $46(20.3)$ & \\
\hline урT2 & $160(19.9)$ & 38 (16.7) & \\
\hline урT3/Т4 & $290(36.1)$ & 95 (41.9) & \\
\hline ypN, n (\%) & & & 0.76 \\
\hline ypNO & 642 (79.9) & $174(76.7)$ & \\
\hline ypN1 & $64(8.0)$ & $20(8.8)$ & \\
\hline ypN2 & 85 (10.6) & $29(12.8)$ & \\
\hline ypN3 & $13(1.6)$ & $4(1.8)$ & \\
\hline Nodes removed, median (IQR) & $18(11-27)$ & $16(11-25)$ & 0.11 \\
\hline Positive STSM, n (\%) & $65(8.1)$ & $16(7.0)$ & 0.71 \\
\hline \multicolumn{4}{|c|}{$\begin{array}{l}\text { IQR = interquartile range; GEM-CIS = gemcitabine cisplatin; DD-MVAC = dose-dense methotrexate, } \\
\text { vinblastine, doxorubicin, cisplatin; GEM-CARBO = gemcitabine carboplatin; } \mathrm{MVAC}=\text { methotrexate, } \\
\text { vinblastine, doxorubicin, cisplatin; NMIBC = non-muscle invasive bladder cancer; STSM = soft tissue surgical } \\
\text { margin } \\
{ }^{*} \text { Mixed histological variant includes adenocarcinoma, neuroendocrine carcinoma and squamous carcinoma }\end{array}$} \\
\hline
\end{tabular}




\begin{tabular}{|c|c|c|c|c|}
\hline \multicolumn{5}{|l|}{ Univariable analysis } \\
\hline & Downstaging & & ypTONO & \\
\hline & OR $(95 \% \mathrm{Cl})$ & $\mathrm{P}$ & OR $(95 \% \mathrm{Cl})$ & $p$ \\
\hline Female vs male sex & $0.92(0.68-1.24)$ & 0.59 & $0.87(0.60-1.23)$ & 0.44 \\
\hline \multicolumn{5}{|l|}{ Smoker } \\
\hline Never & Ref & & ref & \\
\hline Former & $1.06(0.82-1.38)$ & 0.63 & $0.90(0.66-1.22)$ & 0.49 \\
\hline Current & $0.74(0.44-1.24)$ & 0.25 & $0.73(0.37-1.37)$ & 0.35 \\
\hline \multicolumn{5}{|l|}{ Multivariable analysis } \\
\hline & Downstaging & & ypTONO & \\
\hline & OR $(95 \% \mathrm{Cl})$ & $\mathrm{P}$ & OR $(95 \% \mathrm{Cl})$ & $p$ \\
\hline Female vs male sex & $0.82(0.51-1.31)$ & 0.40 & $1.18(0.69-1.98)$ & 0.54 \\
\hline \multicolumn{5}{|l|}{ Smoking status } \\
\hline Never & Ref & & ref & \\
\hline Former & $1.01(0.75-1.36)$ & 0.96 & $1.01(0.72-1.45)$ & 0.93 \\
\hline Current & $0.77(0.43-1.36)$ & 0.37 & $0.75(0.36-1.46)$ & 0.41 \\
\hline \multicolumn{5}{|l|}{ Clinical T stage } \\
\hline cT2 & Ref & & ref & \\
\hline cT3 & $1.31(0.98-1.75)$ & 0.07 & $0.73(0.51-1.03)$ & 0.08 \\
\hline cT4 & $1.29(0.86-1.93)$ & 0.21 & $0.89(0.54-1.41)$ & 0.63 \\
\hline Cisplatin-based chemotherapy & $2.09(1.48-2.99)$ & $<0.01$ & $1.46(0.96-2.28)$ & 0.08 \\
\hline \multicolumn{5}{|l|}{ Chemotherapy cycles } \\
\hline 1 to 2 & Ref & & ref & \\
\hline 3 to 4 & $1.28(0.85-1.94)$ & 0.23 & $1.18(0.73-1.98)$ & 0.52 \\
\hline 5 to 8 & $0.84(0.43-1.60)$ & 0.59 & $0.84(0.36-1.87)$ & 0.68 \\
\hline sexfemale:smokeformer & $1.16(0.62-2.15)$ & 0.64 & $0.57(0.27-1.21)$ & 0.15 \\
\hline \multirow[t]{2}{*}{ sexfemale:smokecurrent } & $1.41(0.29-6.97)$ & 0.66 & $0.50(0.02-3.55)$ & 0.55 \\
\hline & \multicolumn{2}{|c|}{ F-statistics $2.79, p=0.002$} & \multicolumn{2}{|c|}{ F-statistics 1.12, $p=0.34$} \\
\hline
\end{tabular}




\begin{tabular}{|c|c|c|c|c|}
\hline \multicolumn{5}{|l|}{ Univariable analysis } \\
\hline & Downstaging & & ypTONO & \\
\hline & OR $(95 \% \mathrm{Cl})$ & $\mathrm{P}$ & OR $(95 \% \mathrm{Cl})$ & $p$ \\
\hline Age $\geq 50$ years $*$ & & 0.88 & $1.05(0.36-3.80)$ & 0.93 \\
\hline \multicolumn{5}{|l|}{ Smoker } \\
\hline Never & Ref & & ref & \\
\hline Former & $1.19(0.70-2.04)$ & 0.51 & $0.57(0.29-1.10)$ & 0.09 \\
\hline Current & $1.17(0.26-5.21)$ & 0.83 & $0.41(0.02-2.44)$ & 0.41 \\
\hline \multicolumn{5}{|l|}{ Multivariable analysis } \\
\hline & Downstaging & & ypTONO & \\
\hline & OR $(95 \% \mathrm{Cl})$ & $\mathrm{P}$ & OR $(95 \% \mathrm{Cl})$ & $p$ \\
\hline Age $\geq 50$ years $*$ & $0.50(0.11-2.11)$ & 0.35 & $1.25(0.27-9.02)$ & 0.79 \\
\hline \multicolumn{5}{|l|}{ Smoking status } \\
\hline Never & Ref & & ref & \\
\hline Former & $0.37(0.05-2.41)$ & 0.30 & $0.88(0.08-9.33)$ & 0.91 \\
\hline Current & $1.25 e+06(1.35 e-72-N A)$ & 0.99 & $1.60 \mathrm{e}-06(\mathrm{NA}-1.12 \mathrm{e}+72)$ & 0.99 \\
\hline \multicolumn{5}{|l|}{ Clinical T stage } \\
\hline cT2 & Ref & & ref & \\
\hline cT3 & $1.20(0.67-2.14)$ & 0.54 & $0.85(0.41-1.72)$ & 0.67 \\
\hline cT4 & $0.55(0.18-1.51)$ & 0.26 & $0.34(0.05-1.33)$ & 0.17 \\
\hline Cisplatin-based chemotherapy & $2.21(1.02-5.08)$ & 0.05 & $0.96(0.40-2.51)$ & 0.93 \\
\hline \multicolumn{5}{|l|}{ Chemotherapy cycles } \\
\hline 1 to 2 & Ref & & ref & \\
\hline 3 to 4 & $1.41(0.65-3.19)$ & 0.39 & $0.71(0.29-1.83)$ & 0.45 \\
\hline 4 to 8 & $1.61(0.41-6.35)$ & 0.49 & $1.76(0.38-7.73)$ & 0.46 \\
\hline sexfemale:smokeformer & $3.33(0.47-25.6)$ & 0.23 & $0.58(0.05-6.79)$ & 0.65 \\
\hline \multirow[t]{2}{*}{ sexfemale:smokecurrent } & 7.07e-07 (NA - 4.28e+71) & 0.99 & $3.37 e+05(7.43 e-61-N A)$ & 0.99 \\
\hline & \multicolumn{2}{|c|}{ F-statistics $0.89, p=0.54$} & \multicolumn{2}{|c|}{ F-statistics $0.71, p=0.72$} \\
\hline
\end{tabular}


1 Figure 1 - Alluvial diagram for the changes of cT stage to ypT stage in 1031 patients treated 2 with neoadjuvant chemotherapy (NAC) and radical cystectomy for clinically non-metastatic 3 muscle-invasive bladder cancer, stratified by sex

\section{Response to NAC stratified by sex}

Female vs Male $(p=0.005)$

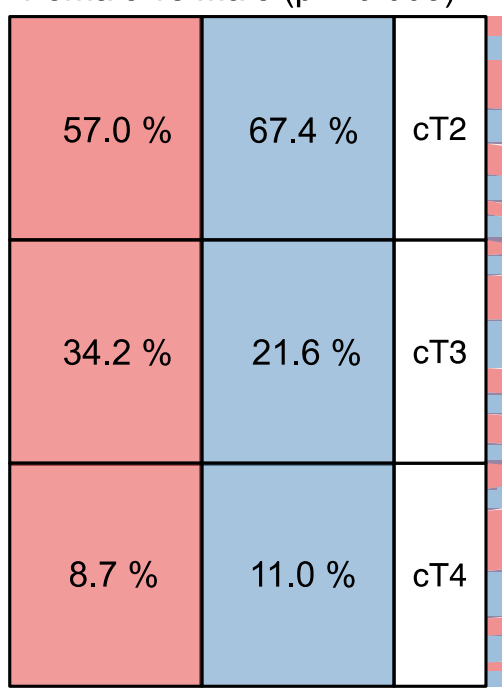

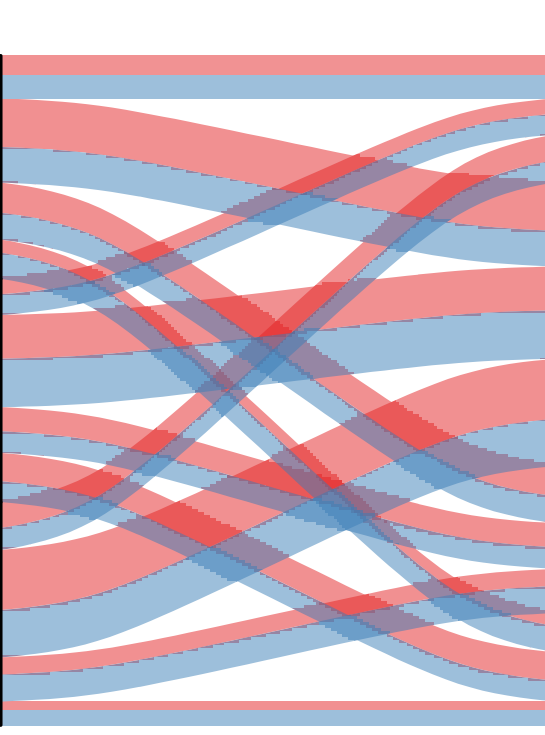

$\operatorname{sex}$

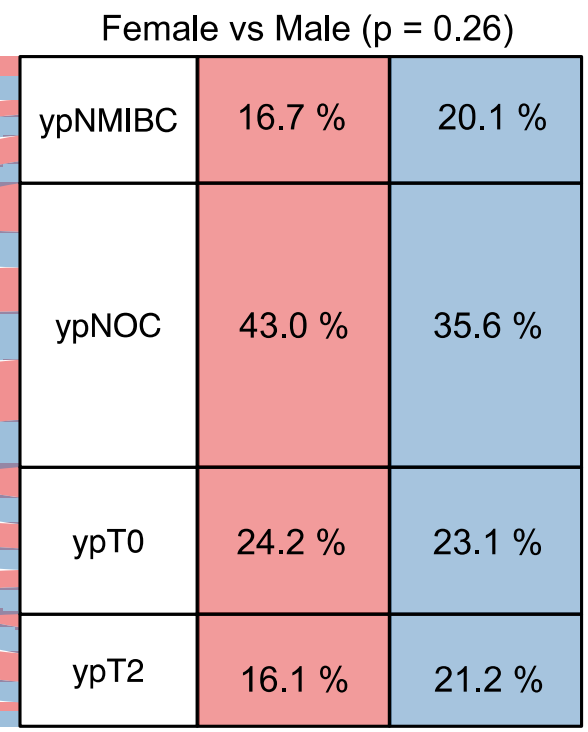

4 5 6

Figure 2 - Kaplan-Maier curves for the association of sex with overall (A) and cancer-specific survival (B) in 718 patients treated with neoadjuvant chemotherapy and radical cystectomy for clinically non-metastatic bladder cancer

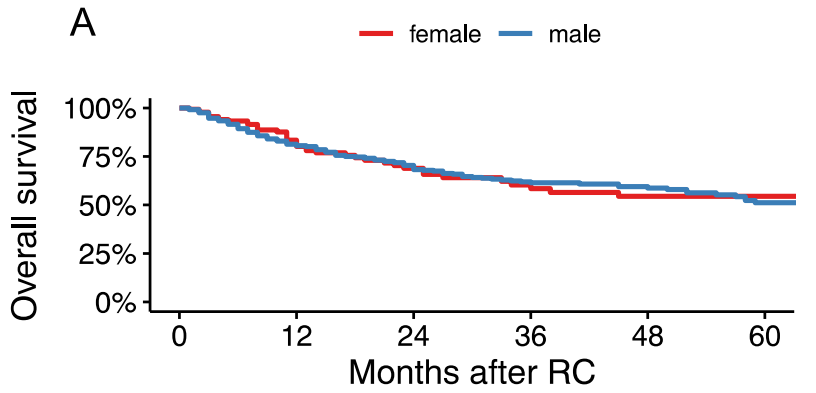

Number at risk



Number at risk

\begin{tabular}{|c|c|c|c|c|c|c|c|c|c|c|}
\hline female 143 & 78 & 47 & 32 & 24 & 14 & female 143 & 78 & 47 & 32 & 24 \\
\hline male 575 & 334 & 195 & 128 & 82 & 48 & male 575 & 334 & 195 & 128 & 82 \\
\hline
\end{tabular}


11 Supplementary Figure S1 - Prevalence of mutated (MT) and wild-type (WT) DNA damage repair 12 (DDR) genes in 106 female and 289 male patients with muscle-invasive bladder cancer. (A) Any 13 DDR gene mutation stratified by sex. (B) Subanalysis of the single DDR genes stratified by sex.

14 Data extracted from The Cancer Genome Atlas Program[13].

A

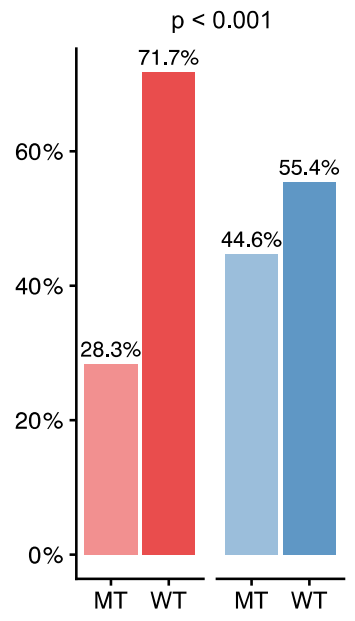

B

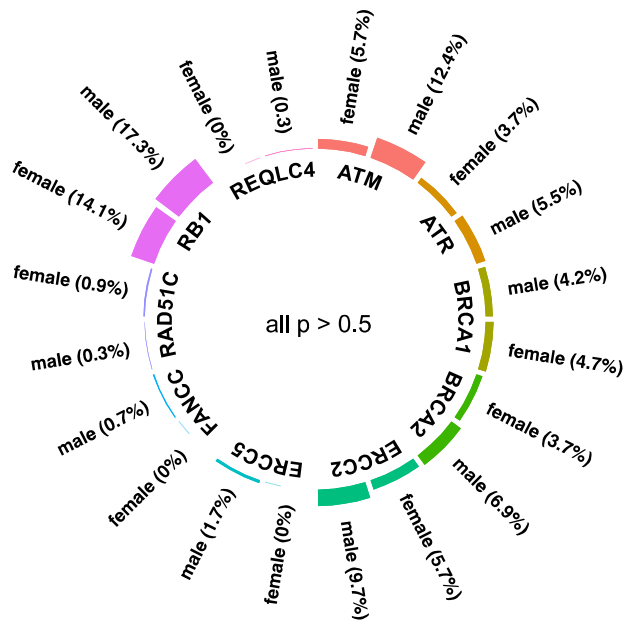

17 Supplementary Figure $\mathbf{S 2}$ - Prevalence of mRNA cluster in 106 female and 289 male patients 18 with muscle-invasive bladder cancer. Data extracted from The Cancer Genome Atlas 19 Program[13].

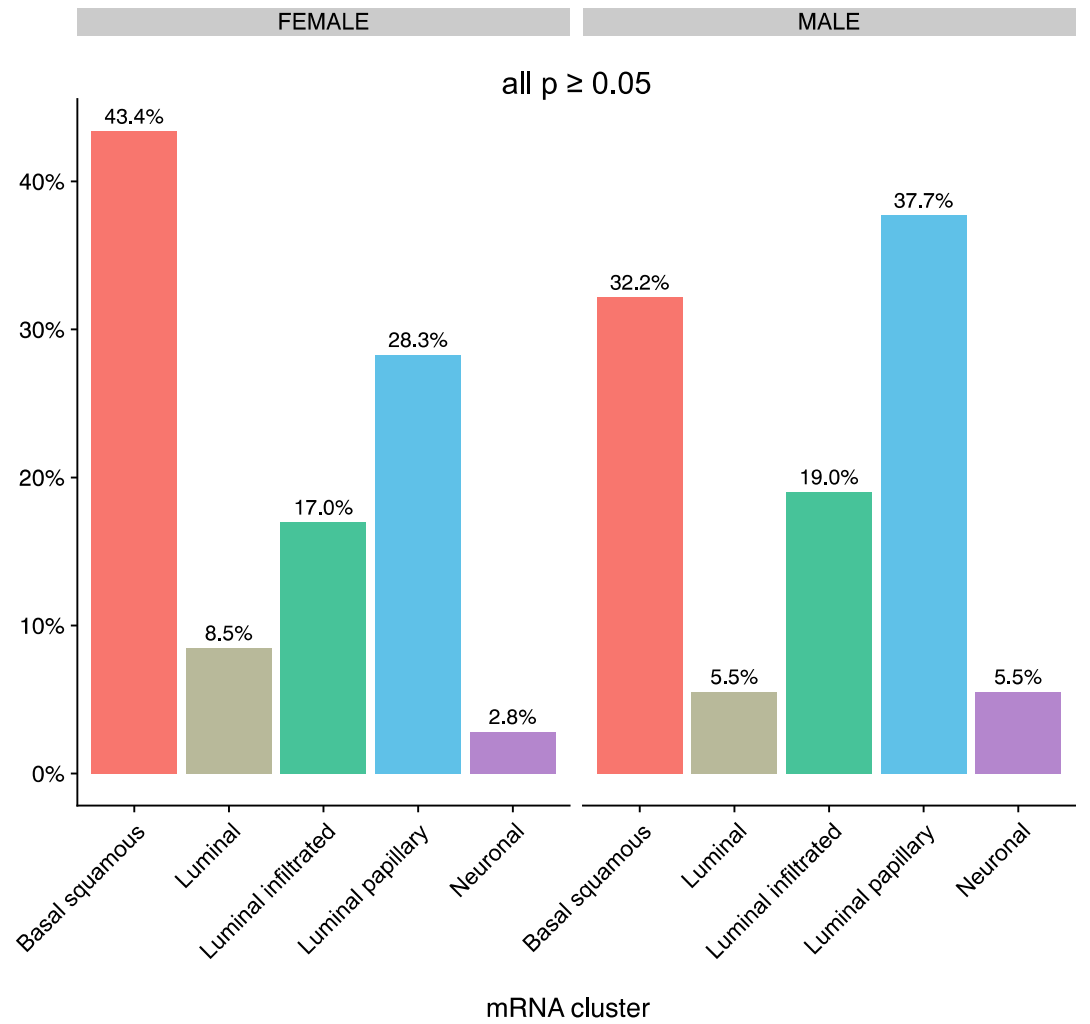




\section{References}

1. Dobruch J, Daneshmand S, Fisch M, et al (2016) Gender and Bladder Cancer: A Collaborative Review of Etiology, Biology, and Outcomes. Eur Urol 69:300-310. https://doi.org/10.1016/j.eururo.2015.08.037

2. Lucca I, Klatte T, Fajkovic H, et al (2015) Gender differences in incidence and outcomes of urothelial and kidney cancer. Nat Rev Urol 12:653. https://doi.org/10.1038/nrurol.2015.257

3. Fajkovic H, Halpern JA, Cha EK, et al (2011) Impact of gender on bladder cancer incidence, staging, and prognosis. World J Urol 29:457-463. https://doi.org/10.1007/s00345-011-0709-9

4. Abdollah F, Gandaglia G, Thuret R, et al (2013) Incidence, survival and mortality rates of stage-specific bladder cancer in United States: A trend analysis. Cancer Epidemiol 37:219-225. https://doi.org/10.1016/j.canep.2013.02.002

5. Shariat SF, Sfakianos JP, Droller MJ, et al (2010) The effect of age and gender on bladder cancer: a critical review of the literature. Bju Int 105:300-308. https://doi.org/10.1111/j.1464410x.2009.09076.x

6. Witjes AJ, Lebret T, Compérat EM, et al (2017) Updated 2016 EAU Guidelines on Muscleinvasive and Metastatic Bladder Cancer. Eur Urol 71:462-475. https://doi.org/10.1016/j.eururo.2016.06.020

7. Zargar H, Espiritu PN, Fairey AS, et al (2015) Multicenter Assessment of Neoadjuvant Chemotherapy for Muscle-invasive Bladder Cancer. Eur Urol 67:241-249. https://doi.org/10.1016/j.eururo.2014.09.007

8. Rose TL, Deal AM, Nielsen ME, et al (2016) Sex disparities in use of chemotherapy and survival in patients with advanced bladder cancer. Cancer 122:2012-2020. https://doi.org/10.1002/cncr.30029

9. KONETY DR, JOSLYN SA (2003) Factors Influencing Aggressive Therapy for Bladder Cancer: An Analysis of Data From the SEER Program. J Urology 170:1765-1771. https://doi.org/10.1097/01.ju.0000091620.86778.2e

10. Scosyrev E, Noyes K, Feng C, Messing E (2009) Sex and racial differences in bladder cancer presentation and mortality in the US. Cancer 115:68-74. https://doi.org/10.1002/cncr.23986

11. Krimphove MJ, Szymaniak J, Marchese M, et al (2019) Sex-specific Differences in the Quality of Treatment of Muscle-invasive Bladder Cancer Do Not Explain the Overall Survival Discrepancy. European Urology Focus. https://doi.org/10.1016/j.euf.2019.06.001

12. Rink M, Fajkovic H, Cha EK, et al (2012) Death Certificates Are Valid for the Determination of 
Cause of Death in Patients With Upper and Lower Tract Urothelial Carcinoma. Eur Urol 61:854855. https://doi.org/10.1016/j.eururo.2011.12.055

13. Robertson GA, Kim J, Al-Ahmadie H, et al (2017) Comprehensive Molecular Characterization of Muscle-Invasive Bladder Cancer. Cell 171:540-556.e25.

https://doi.org/10.1016/j.cell.2017.09.007

14. Allen EM, Mouw KW, Kim P, et al (2014) Somatic ERCC2 Mutations Correlate with Cisplatin Sensitivity in Muscle-Invasive Urothelial Carcinoma. Cancer Discov 4:1140-1153. https://doi.org/10.1158/2159-8290.cd-14-0623

15. Plimack ER, Dunbrack RL, Brennan TA, et al (2015) Defects in DNA Repair Genes Predict Response to Neoadjuvant Cisplatin-based Chemotherapy in Muscle-invasive Bladder Cancer. Eur Urol 68:959-967. https://doi.org/10.1016/j.eururo.2015.07.009

16. Alliance A031701: A Phase II Study of Dose-dense Gemcitabine Plus Cisplatin (ddGC) in Patients with Muscle-invasive Bladder Cancer with Bladder Preservation for Those Patients Whose Tumors Harbor Deleterious DNA Damage Response (DDR) Gene Alterations

17. Gemcitabine, Cisplatin, Plus Nivolumab in Patients With Muscle-invasive Bladder Cancer With Selective Bladder Sparing

18. Risk Adapted Treatment for Muscle Invasive Bladder Cancer After Neoadjuvant Accelerated MVAC

19. Kluth LA, Rieken M, Xylinas E, et al (2014) Gender-specific Differences in Clinicopathologic Outcomes Following Radical Cystectomy: An International Multi-institutional Study of More Than 8000 Patients. Eur Urol 66:913-919. https://doi.org/10.1016/j.eururo.2013.11.040

20. Noon A, Albertsen P, Thomas F, et al (2013) Competing mortality in patients diagnosed with bladder cancer: evidence of undertreatment in the elderly and female patients. Brit J Cancer 108:1534. https://doi.org/10.1038/bjc.2013.106

21. Shariat SF, Milowsky M, Droller MJ (2009) Bladder cancer in the elderly. Urologic Oncol Seminars Orig Investigations 27:653-667. https://doi.org/10.1016/j.urolonc.2009.07.020

22. Conforti F, Pala L, Bagnardi V, et al (2018) Cancer immunotherapy efficacy and patients' sex: a systematic review and meta-analysis. Lancet Oncol 19:737-746. https://doi.org/10.1016/s1470-2045(18)30261-4

23. Rink M, Zabor EC, Furberg H, et al (2013) Impact of Smoking and Smoking Cessation on Outcomes in Bladder Cancer Patients Treated with Radical Cystectomy. Eur Urol 64:456-464. https://doi.org/10.1016/j.eururo.2012.11.039 
24. Crivelli JJ, Xylinas E, Kluth LA, et al (2014) Effect of Smoking on Outcomes of Urothelial Carcinoma: A Systematic Review of the Literature. Eur Urol 65:742-754. https://doi.org/10.1016/j.eururo.2013.06.010

25. Jacob L, Freyn M, Kalder M, et al (2018) Impact of tobacco smoking on the risk of developing 25 different cancers in the UK: a retrospective study of 422,010 patients followed for up to 30 years. Oncotarget 9:17420-17429. https://doi.org/10.18632/oncotarget.24724

26. Janisch F, Shariat SF, Schernhammer E, et al (2019) The interaction of gender and smoking on bladder cancer risks. Curr Opin Urol 1. https://doi.org/10.1097/mou.0000000000000602

27. Krabbe L-M, Svatek RS, Shariat SF, et al (2015) Bladder cancer risk: Use of the PLCO and NLST to identify a suitable screening cohort. Urologic Oncol Seminars Orig Investigations

28. Chen R-J, Ho Y-S, Guo H-R, Wang Y-J (2010) Long-term Nicotine Exposure-Induced Chemoresistance Is Mediated by Activation of Stat3 and Downregulation of ERK1/2 via nAChR and Beta-Adrenoceptors in Human Bladder Cancer Cells. Toxicol Sci 115:118-130. https://doi.org/10.1093/toxsci/kfq028

29. Kim PH, Kent M, Zhao P, et al (2014) The impact of smoking on pathologic response to neoadjuvant cisplatin-based chemotherapy in patients with muscle-invasive bladder cancer. World J Urol 32:453-459. https://doi.org/10.1007/s00345-013-1128-x

30. Boeri L, Soligo M, Frank I, et al (2019) Cigarette smoking is associated with adverse pathological response and increased disease recurrence amongst patients with muscle-invasive bladder cancer treated with cisplatin-based neoadjuvant chemotherapy and radical cystectomy: a single-centre experience. Bju Int. https://doi.org/10.1111/bju.14612

31. Svatek RS, Shariat SF, Lasky RE, et al (2010) The Effectiveness of Off-Protocol Adjuvant Chemotherapy for Patients with Urothelial Carcinoma of the Urinary Bladder. Clin Cancer Res 16:4461-4467. https://doi.org/10.1158/1078-0432.ccr-10-0457

32. Fantini D, Seiler R, Meeks JJ (2018) Molecular footprints of muscle-invasive bladder cancer in smoking and nonsmoking patients. Urologic Oncol Seminars Orig Investigations. https://doi.org/10.1016/j.urolonc.2018.09.017

33. Abufaraj M, Shariat S, Moschini M, et al (2019) 175 The impact of hormones and reproductive factors on the risk of bladder cancer in women: Results from nurses' health study and nurses' health study II. Eur Urol Suppl 18:e235. https://doi.org/10.1016/s15699056(19)30172-1

34. Cantwell MM, Lacey JV, Schairer C, et al (2006) Reproductive factors, exogenous hormone use and bladder cancer risk in a prospective study. Int J Cancer 119:2398--2401. 
35. McGrath M, Michaud DS, Vivo I (2006) Hormonal and Reproductive Factors and the Risk of Bladder Cancer in Women. Am J Epidemiol 163:236-244. https://doi.org/10.1093/aje/kwj028

36. Dietrich K, Demidenko E, Schned A, et al (2011) Parity, early menopause and the incidence of bladder cancer in women: A case-control study and meta-analysis. Eur J Cancer 47:592-599. https://doi.org/10.1016/j.ejca.2010.10.007

37. Apolo AB, Hoffman V, Kaag MG, et al (2015) Summary of the 8th Annual Bladder Cancer Think Tank: Collaborating to move research forward. Urologic Oncol Seminars Orig Investigations 33:53-64. https://doi.org/10.1016/j.urolonc.2014.06.013

38. Choi W, Porten S, Kim S, et al (2014) Identification of Distinct Basal and Luminal Subtypes of Muscle-Invasive Bladder Cancer with Different Sensitivities to Frontline Chemotherapy. Cancer Cell 25:152-165. https://doi.org/10.1016/j.ccr.2014.01.009

39. Petrelli F, Coinu A, Cabiddu M, et al (2014) Correlation of Pathologic Complete Response with Survival After Neoadjuvant Chemotherapy in Bladder Cancer Treated with Cystectomy: A Meta-analysis. Eur Urol 65:350-357. https://doi.org/10.1016/j.eururo.2013.06.049

40. Zargar H, Zargar-Shoshtari K, Lotan Y, et al (2016) Final Pathological Stage after Neoadjuvant Chemotherapy and Radical Cystectomy for Bladder Cancer-Does pTO Predict Better Survival than pTa/Tis/T1? J Urology 195:886-893. https://doi.org/10.1016/j.juro.2015.10.133

41. Messer JC, Shariat SF, Dinney CP, et al (2014) Female Gender Is Associated With a Worse Survival After Radical Cystectomy for Urothelial Carcinoma of the Bladder: A Competing Risk Analysis. Urology 83:863-868. https://doi.org/10.1016/j.urology.2013.10.060

42. Lee RK, Abol-Enein $\mathrm{H}$, Artibani W, et al (2014) Urinary diversion after radical cystectomy for bladder cancer: options, patient selection, and outcomes. Bju Int 113:11-23.

https://doi.org/10.1111/bju.12121

43. James AC, Lee FC, Izard JP, et al (2014) Role of Maximal Endoscopic Resection Before Cystectomy for Invasive Urothelial Bladder Cancer. Clin Genitourin Canc 12:287-291. https://doi.org/10.1016/j.clgc.2014.01.005

44. Zargar-Shoshtari K, Zargar H, Lotan Y, et al (2016) A Multi-Institutional Analysis of Outcomes of Patients with Clinically Node Positive Urothelial Bladder Cancer Treated with Induction Chemotherapy and Radical Cystectomy. J Urology 195:53--59. https://doi.org/10.1016/j.juro.2015.07.085

45. Rink M, Chun FK, Dahlem R, et al (2012) Prognostic Role and HER2 Expression of Circulating Tumor Cells in Peripheral Blood of Patients Prior to Radical Cystectomy: A Prospective Study. 
197 Eur Urol 61:810-817. https://doi.org/10.1016/j.eururo.2012.01.017

198

46. Ploussard G, Daneshmand S, Efstathiou JA, et al (2014) Critical Analysis of Bladder Sparing

200 with Trimodal Therapy in Muscle-invasive Bladder Cancer: A Systematic Review. Eur Urol

201 66:120-137. https://doi.org/10.1016/j.eururo.2014.02.038

202 